\title{
Estado morfodinâmico praial no instante da observação: uma alternativa de identificação
}

\author{
(Beach morphodynamic state at the moment of observation: an \\ alternative for identification)
}

\author{
Dieter Muehe* \\ Universidade Federal do Rio de Janeiro \\ (Laboratório de Geomorfologia Fluvial, Costeira e Submarina. Departamento de Geografia) \\ (Instituição participante de Programa de Geologia e Geofísica Marinha - PGGM) \\ *e-mail: dtrmuehe@igeo.ufrj.br
}

- Abstract: Determinations of the morphodynamic state of beach and surf zone were made on four beaches in Rio de Janeiro state, with two beaches located northward and two westward of Cabo Frio. Twenty four monthly measurements of beach and surf zone profiles associated to measurements of wave height and period, sediment settling velocity as well as swash climate were made during low spring tide. The beaches were classified by their modal morphodynamic state, a differentiation due to different wave climate and sediment characteristics. With exception for the reflective state, low correlation between the predicted and observed Morphodynamic State were obtained using Dean's parameter $(\Omega)$. This is a consequence of the low correlation between the grain size (and settling velocity) of the beach face sediments and the topographic gradient, when applied to a single beach. A new approach for the identification of the Morphodynamic State is proposed by inferring the beach and nearshore morphology through the comparison of the wave height and period in the outer breaker zone to the height and semi-period of wave in the swash zone.

- Resumo: Para a determinação do estado morfodinâmico modal de algumas praias do estado do Rio de Janeiro, foram realizados perfis topográficos transversais acompanhado de medições oceanográficas e sedimentológicas durante vinte e quatro campanhas mensais em condições de baixa-mar de sizígia em quatro praias, estando duas localizadas a norte e duas a oeste do Cabo Frio. As mesmas se diferenciaram pelo clima de ondas, pelas suas características sedimentológicas expressas em termos de velocidade de decantação e conseqüentemente pelo estado modal. A utilização do parâmetro $\Omega$ de Dean para a identificação do estado morfodinâmico no momento da observação apresentou resultados geralmente insatisfatórios, com exceção do estado refletivo, devido à baixa correlação entre a velocidade de decantação dos sedimentos da face da praia e o gradiente topográfico. Uma nova abordagem de determinação do estado morfodinâmico, no momento da observação, é proposta através da inferência da morfologia da praia e zona de surfe e arrebentação por meio da comparação da altura e período da onda significativa na zona de arrebentação externa e a altura e duração do espraiamento da onda na face da praia.

- Descriptors: Beach morphodynamic, Beach state model, Swash climate, Rio de Janeiro State, Brazil.

- Descritores: Praia, Morfodinâmica, Estado morfodinâmico, Clima de espraiamento. 


\section{Introdução}

O perfil topográfico transversal a uma praia e a sua variabilidade é o resultado, principalmente, de sua granulometria e do clima de ondas. Assim, praias de granulometria grossa, expostas a um ambiente de alta energia, tendem a apresentar um perfil refletivo, com uma face de praia íngreme e berma elevada, o contrário ocorrendo em praias com areia finá, que representam um perfil dissipativo.

Tentativas de prever a resposta morfológica de uma praia às condições oceanográficas vem sendo objeto de pesquisa desde as primeiras constatações das modificações cíclicas entre perfil de inverno, com perda de areia do prisma praial, e perfil de verão, com o retorno da areia erodida durante as tempestade de inverno (Shepard, 1950), ou simplesmente como alternância entre perfil de tempestade e perfil de tempo bom ou de marulho (Komar, 1976). Entre os diversos modelos e índices do estado morfológico, o de maior aceitação, e um dos mais compreensíveis, é o de Wright \& Short $(1983,1984)$. Neste modelo, que inclui a morfologia da zona de arrebentação e surfe, foram identificados, além dos dois estados morfológicos extremos, o dissipativo e o refletivo, mais quatro estados intermediários: o Banco e Calha Longitudinal (BCL), o Banco e Praia de Cúspides (BPC), o Bancos Transversais (BT) e o Terraço de Baixa Mar (TBM). Estes seis estados foram posteriormente relacionados por Wright et al. (1985) ao parâmetro $(\Omega)$ de Dean (1973) sendo:

$$
\Omega=\frac{H_{b}}{\varpi_{s} T}
$$

onde $\mathrm{Hb}$ é a altura da onda na arrebentação, $\omega_{\mathrm{S}}$ a velocidade mediana de decantação dos grãos e $T$ o período da onda. Os valores médios e desvio padrão respectivos para os diversos estados são os seguintes:

$\begin{array}{lcc}\text { Estado } & \bar{\Omega} & \text { Desvio Padrão } \\ \text { Refletivo } & \leq 1,5 & - \\ \text { Terraço de Baixa Mar (TBM) } & 2,40 & 0,19 \\ \text { Bancos Transversais (BT) } & 3,15 & 0,64 \\ \text { Banco e Praia de Cúspides (BPC) } & 3,50 & 0,76 \\ \text { Banco e calha longitudinal (BCL) } & 4,70 & 0,93 \\ \text { Dissipativo } & >5,5 & -\end{array}$

Desequilíbrios existem quando o valor de $\Omega$ não corresponde ao estado previsto o que permite avaliar a direção de evolução da praia na busca de recuperação do equilibrio. É preciso, porém, considerar que a correlação obtida, nos estudos realizados na Australia, entre o valor de $\Omega$ e o estado da praia, no momento da observação, ter sido baixa, sendo que o valor utilizado foi o da média ponderada das condições com alguns dias de antecedência. Isto naturalmente aumenta a dificuldade de aplicação deste modelo pelo esforço adicional a ser feito no levantamento das variáveis.

Uma outra maneira de relacionar o estado morfodinâmico às condiçóes oceanográficas foi apresentado por MacArdle \& MacLachlan (1992) que, com o objetivo de melhor caracterizar as condições de fluxo na face da praia, para fins de correlação com variáveis da macrofauna bêntica, substituiram os parâmetros da onda e do sedimento por parâmetros do clima de espraiamento da onda na face da praia (swash climate).

O objetivo do presente estudo é o de apresentar os resultados e uma avaliação crítica da aplicação do parâmetro de Dean e dos parâmetros de clima de espraiamento a diversos tipos de praias do litoral do estado do Rio de Janeiro, submetidas a condições oceanográficas distintas.

\section{Caracterização das áreas de estudo}

As estações de monitoramento foram localizadas em quatro pontos do litoral a norte e a oeste do Cabo Frio (RJ), considerando aspectos de diferenciação, como grau de exposição às ondas e a granulometria dos sedimentos da praia (Fig. 1).

A estação 1 se localiza no flanco sul da planície costeira do rio Paraíba do Sul (Cabo São Tomé), é caracterizada por areias grossas a muito grossas, face da praia íngreme, berma estreita e elevada. $O$ fundo marinho, ao contrário da praia, é recoberto por sedimentos arenosos muito finos, oriundos do rio Macaé, resultando num gradiente topográfico muito suave. Como conseqüência a transição da face da praia para o fundo marinho adjacente se faz de modo abrupto, a zona de surfe é praticamente ausente e as ondas, com altura média na arrebentação de $1,5 \mathrm{~m}$, arrebentam na base da face da praia dissipando a quase totalidade de sua energia na face da praia onde geram fluxos de espraiamento e refluxo de elevada velocidade que chega freqüentemente a mais de $300 \mathrm{~cm} / \mathrm{s}$.

A estação 2 se localiza aproximadamente no centro do litoral do embaiamento Rio das Ostras Cabo Búzios, a sul da desembocadura do rio São João. Protegida da ação direta das ondas de tempestade vindas do sul, é submetida às ondas de nordeste que atingem a zona de arrebentação com altura média um pouco abaixo de $1 \mathrm{~m}$. A face da praia e o fundo marinho, originalmente compostos por areia reliquiar de textura média a grossa, são recobertos por areias muito finas a silte grosso, oriundos do rio São João. O gradiente, de ambas as feições, e muito suave, fazendo com que as ondas arrebentem em sucessivas 


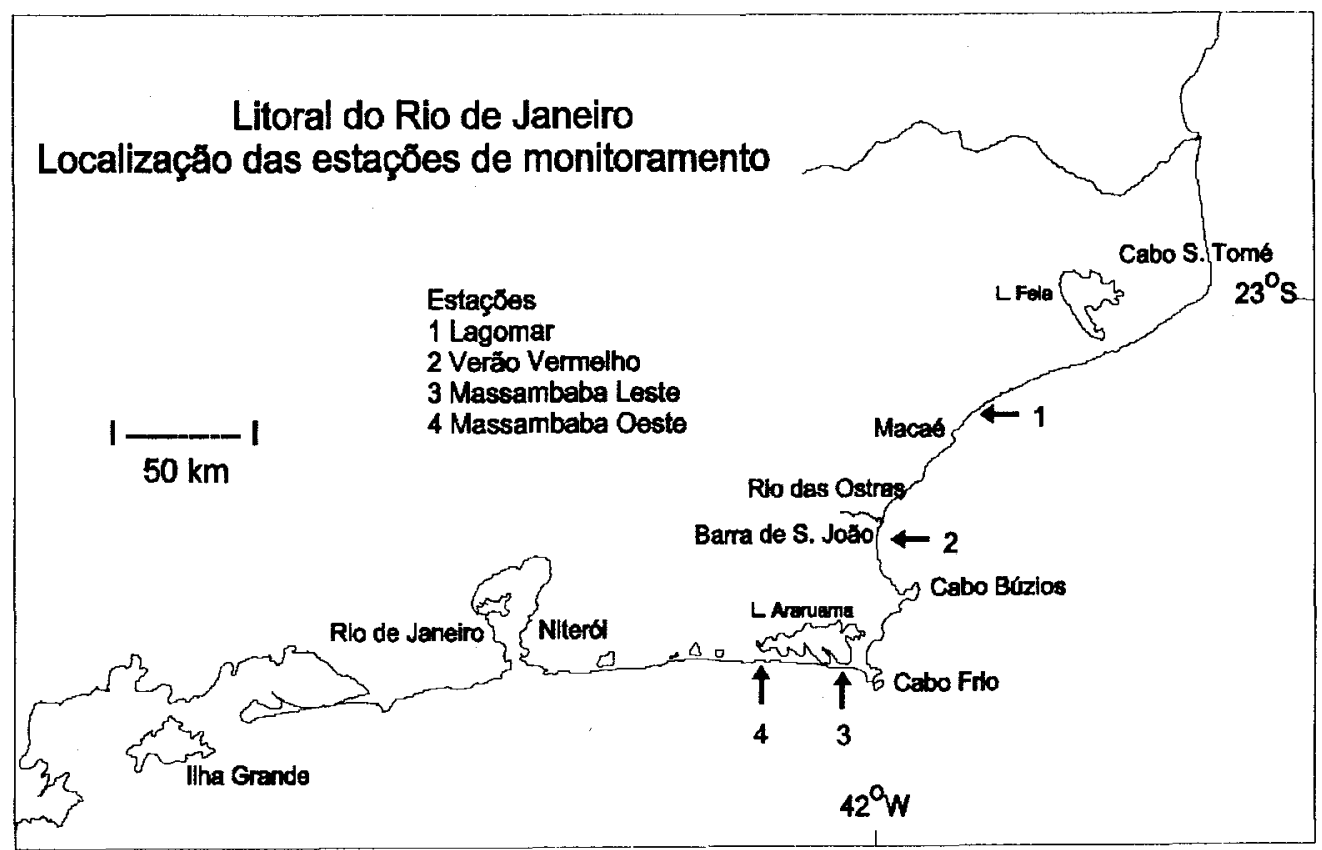

Fig. 1. Localização das estações de monitoramento dos perfis de praia.

linhas de arrebentação e mantenham a face da praia quase que permanentemente saturada, já que o refluxo da onda não se completa antes da chegada de uma nova onda.

As estações 3 e 4, ambas localizadas na praia da Massambaba, se apresentam expostas a níveis extremamente elevados de energia, sendo que alturas de onda, com mais de $4 \mathrm{~m}$ na arrebentação, não são infrequientes durante as tempestades vindas doquadrante sul. $O$ arco praial, como um todo, segue a granulometria da plataforma continental interna (Muehe \& Carvalho, 1993), apresentando um gradiente de decréscimo granulométrico contínuo em direção ao Cabo Frio, com areias muito bem selecionadas. Assim, a estação 3, Massambaba leste, apresenta granulometria mais fina que a estação 4, Massambaba oeste, o que se reflete no perfil submarino, mais suave a leste, devido à presença freqüente de um banco submarino.

\section{Material e métodos}

\section{Medição do perfil topográfico}

Nos locais previstos para o levantamento de cada perfil foi determinada a orientação dos mesmos, buscando estabelecer uma direcão perpendicular à linha de praia. Esta orientação foi definida, por meio de aproximações, através da medição, com bússola de geólogo, da direção geral do escarpamento da pós-praia e do mergulho da face da praia.

Uma vez definida a direção do perfil foram cravados tubos plásticos de $1,5 \mathrm{~m}$ de comprimento e 7,5 $\mathrm{cm}$ de diâmetro, cujo posicionamento, ao longo do perfil, foi feito por meio de teodolito. Na parte interna de cada tubo foi cravada uma estaca de madeira, cujo topo ficou nivelado com o topo do tubo plástico. Este conjunto de tubos, além de fixar a direção do perfil, teve sua altura definida a partir da determinação aproximada do nível médio do mar através do nivelamento topográfico em combinação com a curva de maré de previsão horária fornecida pela Diretoria de Hidrografia e Navegação (DHN).

Feita a fixação dos marcos topográficos, foi realizado um nivelamento por meio do teodolito, desde o reverso do cordão litorâneo até o ponto de refluxo máximo da onda na face da praia, para a caracterização tanto da porção estável do perfil quanto da praia propriamente dita.

O levantamento dos perfis de praia foi realizado com periodicidade mensal, em situação de baixa mar de sizígia, através do método das balizas (Emery, 
1961). Este método utiliza duas balizas de mesmo comprimento, graduadas em centímetros. A diferença de altura entre as duas balizas, refletindo a topografia, é determinada pela interseção, na baliza mais alta, da linha imaginária que liga a linha do horizonte com o topo da baliza mais baixa. $O$ gradiente da face da praia ativa, isto é a parte da face da praia alcançada pelas ondas por ocasião do levantamento, foi posteriormente determinado a partir do perfil levantado no campo.

Para o levantamento do perfil submarino a metodologia empregada para a definição da topografia na zona de surfe depende do estado do mar e do gradiente submarino. Sob condições de mar calmo o nivelamento foi feito por meio de teodolito com o portador da mira topográfica avançando mar adentro. Neste caso, além da determinação da altura, é feita a leitura estadimétrica, permitindo determinar a distância a partir da leitura na mira.

Para facilitar a determinação do perfil submarino foi construído um trenó submarino (Muehe \& Souza, 1997), de estrutura tubular que, utilizando uma tábua de vai e vem, é impulsionado pelo refluxo da onda através da arrebentação (Fig. 2). Com um mastro de 6 m de altura, constituído por uma mira topográfica fixada numa base a $2 \mathrm{~m}$ acima do fundo, a determinação da topografia é feita através de nivelamento topográfico e estadimetria. Concluído o perfil o trenó é puxado de volta para a praia por meio de um guincho.

\section{Medição de parâmetros morfodinâmicos}

Em cada perfil de praia foram realizadas observações de altura $\left(\mathrm{H}_{b}\right)$, período $(\mathrm{T})$ e obliquidade de incidência da onda $\left(\alpha_{b}\right)$ na arrebentação. A altura da onda foi medida com utilização de mira topográfica levada até ao ponto próximo do refluxo da onda e com um observador lendo a altura na intercessão da linha imaginária ligando o horizonte à crista da onda com a mira. Procurou-se caracterizar a onda significativa, considerando a tendência natural ao intuitivamente descrever o estado do mar. $\mathrm{O}$ período foi determinado pela contagem do tempo de onze seqüências de arrebentações das ondas, dividido por dez. No caso de ondas arrebentando em múltiplas linhas de arrebentação considerou-se a arrebentação mais externa. A determinação do estado da praia, por ocasião do levantamento, foi feita por avaliação individual de mais de um componente do grupo de pesquisa e posterior definição consensual.

Para caracterizar o regime de espraiamentorefluxo da onda (swash climate), na face da praia, ou simplesmente regime de espraiamento, foram realizadas as medidas propostas por McArdle \& McLachlan (1992), quais sejam: a distância do espraiamento, medida entre o refluxo máximo da onda, na base da face da praia e o alcance máximo de espraiamento, duração e velocidade do espraiamento, período do espraiamento - refluxo, que é o intervalo de tempo correspondente ao ciclo espraiamentorefluxo, e o gradiente da face da praia.

Kemp \& Plinston (1968) estabeleceram a relação $T_{S} / T$, para caracterizar o regime de fluxo através da relação entre a duração do espraiamento (Ts) e o período da onda (T):

$$
\begin{aligned}
& \mathrm{T}_{\mathrm{S}} / \mathrm{T}<0,5 \text { fase baixa } \\
& 0,5<\mathrm{T}_{\mathrm{S}} / \mathrm{T}<1,0 \text { fase média } \\
& \mathrm{T}_{\mathrm{S}} / \mathrm{T}>1,0 \text { fase alta }
\end{aligned}
$$

$\mathrm{Na}$ fase baixa, o fluxo de espraiamento e refluxo se completam antes da chegada de uma nova onda. $\mathrm{Na}$ fase média, o ciclo é interrompido pela chegada de uma nova onda antes de completar o refluxo, gerando turbulência na parte inferior da face da praia. $\mathrm{Na}$ fase alta, não ocorre o refluxo pois a freqüência de chegada das ondas é muito maior que o tempo para completar o ciclo de espraiamento-refluxo. Neste caso, o escoamento da água acumulada na face da praia tem que ocorrer por percolação e fluxo lateral.

Para a avaliação do volume $\mathrm{e}$ direção de transporte de areia na praia foi empregada a seguinte relação empírica entre o volume transportado $\left(Q_{S}\right)$, em $\mathrm{m}^{3} /$ dia, e o fluxo de energia da onda $\left(P_{1}\right)$, encontrada por Komar (1983):

$$
Q_{s}=3,4(E C n)_{b} \operatorname{sen} \alpha_{b} \cos \alpha_{b}
$$

onde $\mathrm{E}$ representa a energia da onda na arrebentação, calculada para a altura significativa $\left(E=\frac{1}{8} \rho g H^{2}\right)$, $\mathrm{g}$, a aceleração da gravidade $\left(9,81 \mathrm{~m} / \mathrm{s}^{2}\right), \mathrm{Cn}$, a velocidade de grupo das ondas, sendo $n=1$ para águas rasas, $\rho$ a densidade da água, e $\alpha_{b} o$ ângulo de incidência da arrebentação em relação à linha de praia.

\section{Amostragem e análise de sedimento}

Amostras de sedimentos superficiais foram coletadas em cada perfil, na metade da face da praia, para determinação de sua velocidade de decantação. Usou-se para isto o tubo de sedimentação idealizado por Emery (Emery, 1938; Muehe, 1996). 


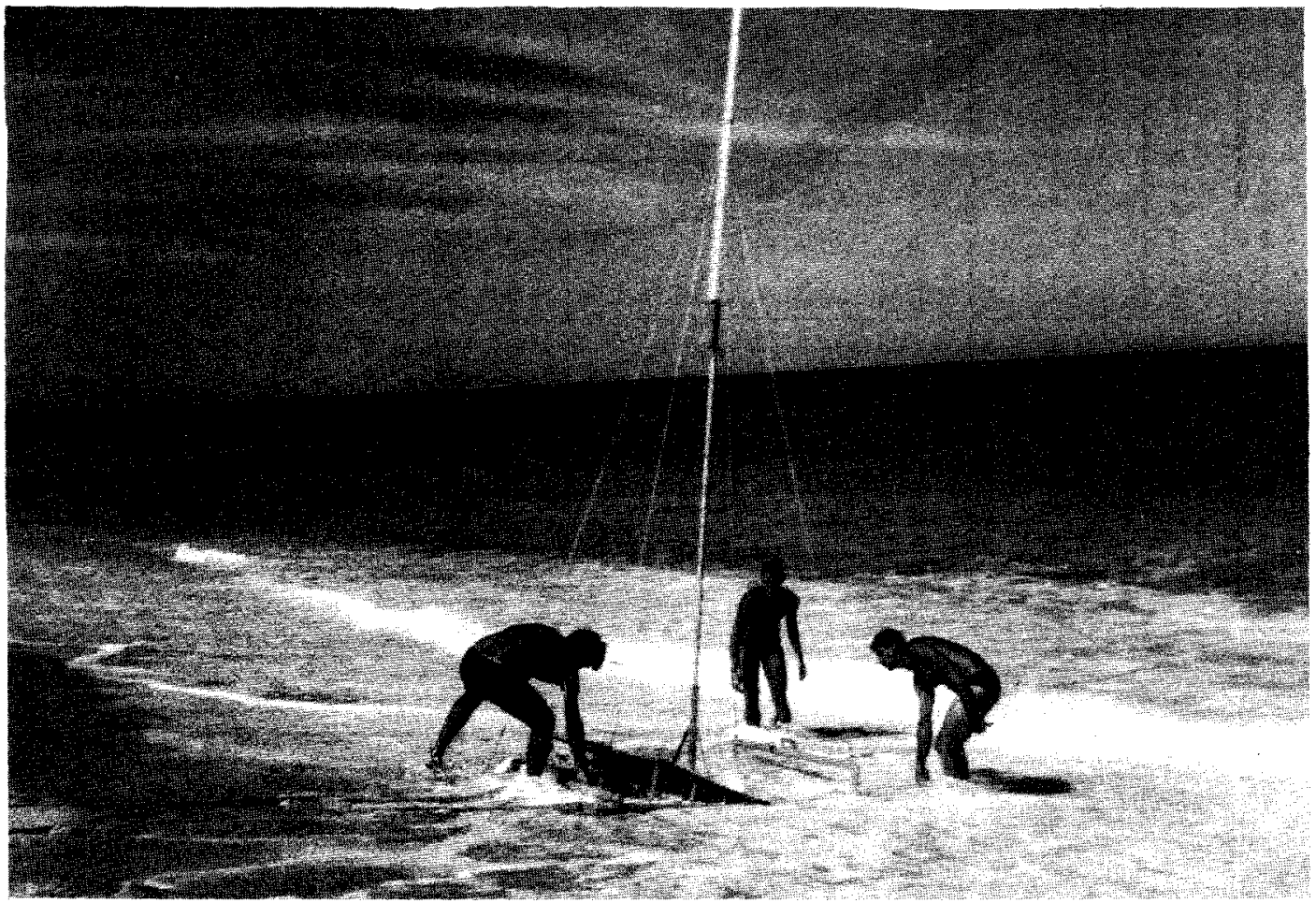

Fig. 2. Preparação para lançamento do trenó submarino.

\section{Resultados}

Morfodinâmica da praia e fundo marinho
adjacente

A Figura 3 representa a superposição do conjunto de perfis levantado em cada uma das estações de monitoramento.

$\mathrm{Na}$ Tabela 1 estão sumarizadas as médias e desvio padrão correspondente, das variáveis monitoradas durante as vinte e quatro campanhas. Em termos oceanográficos verifica-se que as maiores ondas significativas na arrebentação $\left(\mathrm{H}_{b}\right)$ ocorrem na praia da Massambaba, diretamente exposta às ondas do quadrante sul, seguido de Lagomar e Verão Vermelho. Esta última, por estar protegida das ondas de tempestade pelo Cabo Búzios, reflete essencialmente as características das ondas de Nordeste. $\mathrm{O}$ transporte litorâneo de sedimentos $\left(\mathrm{Q}_{\mathrm{s}}\right)$, em Lagomar e Verão Vermelho, é predominantemente para norte. Já nas duas estações da Massambaba, a direção resultante, para leste, não é significativa quando se considera o elevado valor do desvio padrão associado, sendo que a tendência é mais no sentido de um equilibrio entre as duas direções de transporte. Morfologicamente a declividade da face da praia, reflexo da granulometria e do nível de energia das ondas, é máxima em Lagomar $\left(8^{\circ}\right)$ com os sedimentos da face da praia apresentando uma velocidade de decantação $\left(\omega_{\mathrm{s}}\right)$ de $0,15 \mathrm{~m} / \mathrm{s}$, seguido de Massambaba oeste $\left(7^{\circ} ; 0,10 \mathrm{~m} / \mathrm{s}\right)$, Massambaba leste $\left(5^{\circ} ; 0,06 \mathrm{~m} / \mathrm{s}\right)$ e Verão Vermelho $\left(2^{\circ} ; 0,03 \mathrm{~m} / \mathrm{s}\right)$. A configuração média do perfil subaéreo da praia, expressa, segundo Sonu \& Van Beek (1971), pela relação entre a área abaixo do perfil (S) e o produto entre a largura $(\lambda)$ e a altura (h) do perfil ativo da praia indica um perfil com tendência linear $(\lambda \mathrm{h}=0,5)$ para as praias Lagomar, Verão Vermelho e Massambaba oeste, e convexo $(S / \lambda h>0,5)$ para Massambaba leste.

As correlações lineares entre os diversos parâmetros levantados mostra, considerando todo o conjunto de praias, que as variáveis do clima de espraiamento na face da praia (clima de swash), são as que melhor traduzem a relação entre o subsistema oceânico e o subsistema morfológico (Fig. 4). Assim, a altura da onda se correlaciona positivamente com a velocidade de espraiamento e a distância de espraiamento, que por sua vez se correlacionam positivamente com a velocidade de decantação dos sedimentos e com a declividade da face da praia. A única variável oceânica que se correlaciona com o subsistema morfológico é a esbeltez da onda, porém com coeficiente de correlação mais baixo que as variáveis do clima de espraiamento. 


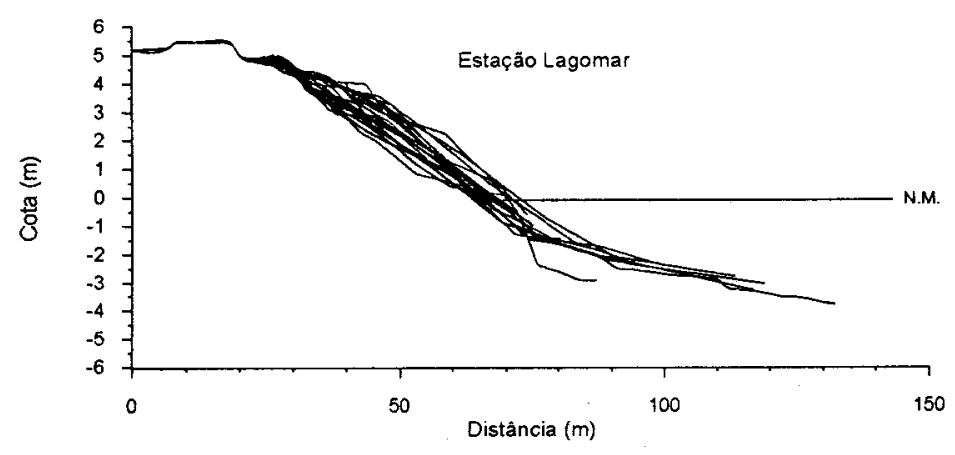

Praia refletiva. $\Omega=1,01 ; \sigma=0,31.100 \%$ de concordância entre observado e calculado.

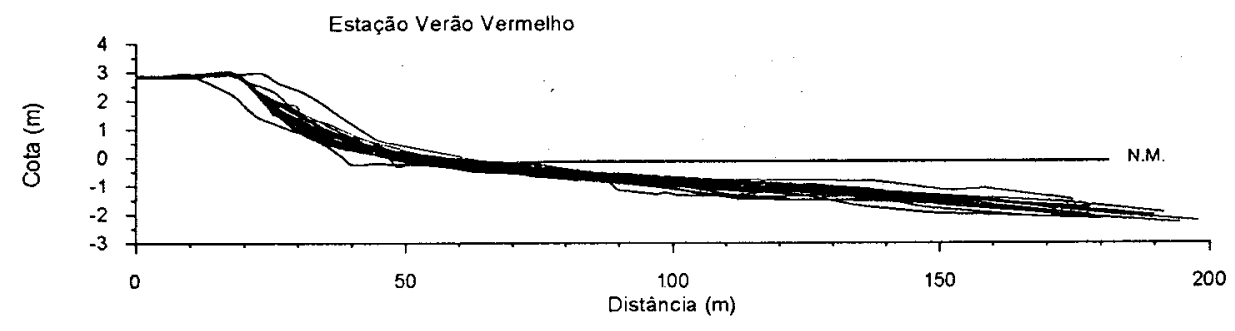

Praia dissipativa. $\Omega=4,51 ; \sigma=2,90.50 \%$ de discordância entre observado e calculado.

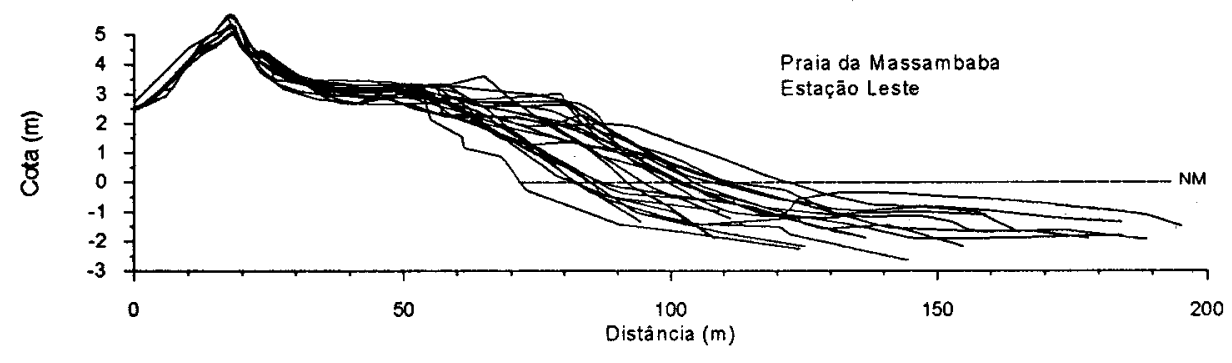

Praia intermediária, variando entre refletiva a TBM; BT; BPC. $\Omega=2,89 ; \sigma=1,12.42 \%$ de discordância entre observado e calculado.

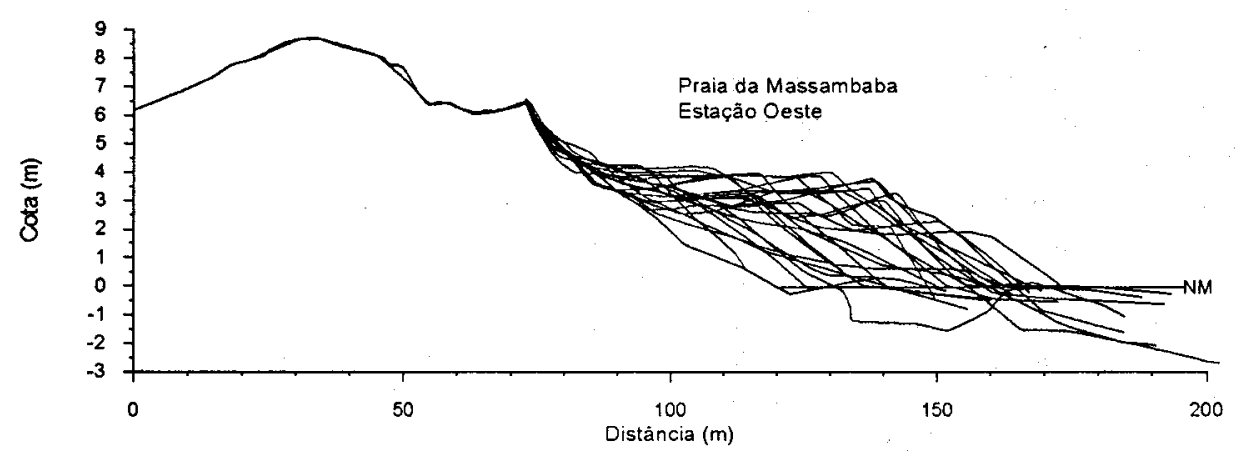

Praia intermediária variando entre refletiva a TBM. $\Omega=1,88 ; \sigma=0,61.46 \%$ de discordância entre observado e calculado.

Fig. 3. Superposição dos perfis das campanhas 1 a 24 . 
Tab 1. Parâmetros oceanográficos e morfodinâmicos médios (e respectivo desvio padrão).

\begin{tabular}{|c|c|c|c|c|c|c|c|c|c|c|}
\hline Local & $\begin{array}{l}\mathrm{Hb}_{\mathrm{s}} \\
\text { (m) }\end{array}$ & $\begin{array}{c}T \\
\text { (s) }\end{array}$ & $\begin{array}{c}\text { Incidéncia } \\
\text { graus }\end{array}$ & $\begin{array}{c}\text { Direçắo } \\
\text { Transporte }\end{array}$ & $\mathrm{H}_{0} \mathrm{~L}_{0}$ & $\begin{array}{c}\mathrm{Qs} \\
\mathrm{m}^{3 / 2} / \mathrm{dia}\end{array}$ & $\begin{array}{c}\text { Espraiam. } \\
(\mathrm{m})\end{array}$ & $\begin{array}{l}\text { Espraiam. } \\
\text { (s) }\end{array}$ & $\begin{array}{l}\text { Espr.Reflux } \\
\text { (s) }\end{array}$ & $\begin{array}{c}\text { Espraiam } \\
(\mathrm{m} / \mathrm{s})\end{array}$ \\
\hline Lagomar & $7,50(0,38)$ & $10,53(1,59)$ & $3(15)$ & Norte & $0,009(0,005)$ & $5624(14544)$ & $16(3,42)$ & $5,5(0,87)$ & $10,56(1,48)$ & $3,01(0,52)$ \\
\hline Verấo Vemelho & $0,88(0,29)$ & $9,92(2,49)$ & $3(7)$ & Norte & $0,007(0,005)$ & $5212(1858)$ & $13(5,62)$ & $11,9(5,16)$ & $20,88(7,62)$ & $1,14(0,23)$ \\
\hline Massambaba Leste & $2,06(0,99)$ & $12,34(2,01)$ & $2(9)$ & Leste & $0,008(0,003)$ & 14823 (34637 & $18(6,90)$ & $8,19(3,06)$ & $15,44(4,14)$ & $2,20(0,60)$ \\
\hline Massembeba Oeste & $2,06(0,70)$ & $11,21(1,55)$ & $2(8)$ & Leste & $0,010(0,003)$ & $6798(21052$ & $16(8,35)$ & $6,90(3,81)$ & $13,03(5,83)$ & $2,44(0,70)$ \\
\hline
\end{tabular}

\begin{tabular}{|c|c|c|c|c|c|c|c|c|c|c|}
\hline Local & $T_{\text {dopor }} / T$ & $\begin{array}{c}\text { Gradiente } \\
(\tan \beta)\end{array}$ & $\begin{array}{c}\omega_{s} \\
(\mathrm{~m} / \mathrm{s})\end{array}$ & $\begin{array}{l}\text { Dean's } \\
(\Omega)\end{array}$ & $\begin{array}{l}\text { Volume (Q) } \\
\left.\text { (m } \mathrm{m}^{3} / \mathrm{dia}\right)\end{array}$ & $\begin{array}{l}\text { Largura }(\lambda) \\
(m)\end{array}$ & $\begin{array}{c}\text { Altura (h) } \\
(\mathrm{m})\end{array}$ & $Q / a h$ & $\begin{array}{l}\Delta \mathrm{Vol} . \\
\mathrm{m}^{3}\end{array}$ & $\begin{array}{l}\mathrm{T}_{\sin } \\
{ }^{\circ} \mathrm{C}\end{array}$ \\
\hline Lagomar & $0,53(0,09)$ & $0,147(0,024)$ & $0,15(0,03)$ & $1,01(0,31)$ & $130(13,46)$ & $47(2,8)$ & $5,0(0,00)$ & $0,56(0,04)$ & $1,07(13,07)$ & $23,04(2,3)$ \\
\hline Verão Vermelho & $1,30(0,77)$ & $0,031(0,016)$ & $0,03(0,02)$ & $4,51(2,90)$ & $53(7,19)$ & $38(4,4)$ & $2,9(4,35)$ & $0,49(0,06)$ & $0,05(8,07)$ & $24,43(2,6)$ \\
\hline Massambaba Leste & $0,68(0,29)$ & $0,081(0,026)$ & $0,06(0,00)$ & $2,89(1,12)$ & $169(29,01)$ & $69(13,7)$ & $3,5(0,21)$ & $0,7+(0.09)$ & $1,19(34,97)$ & $20,48(3,2)$ \\
\hline Massambaba Oeste & $0,62(0,33)$ & $0,129(0,039)$ & $0,10(0,01)$ & $1,88(0,61)$ & $233(52,43)$ & $79(17,2)$ & $6,3(0,79)$ & $0,49(0,16)$ & $1,58(52,61)$ & $21,12(3,4)$ \\
\hline
\end{tabular}

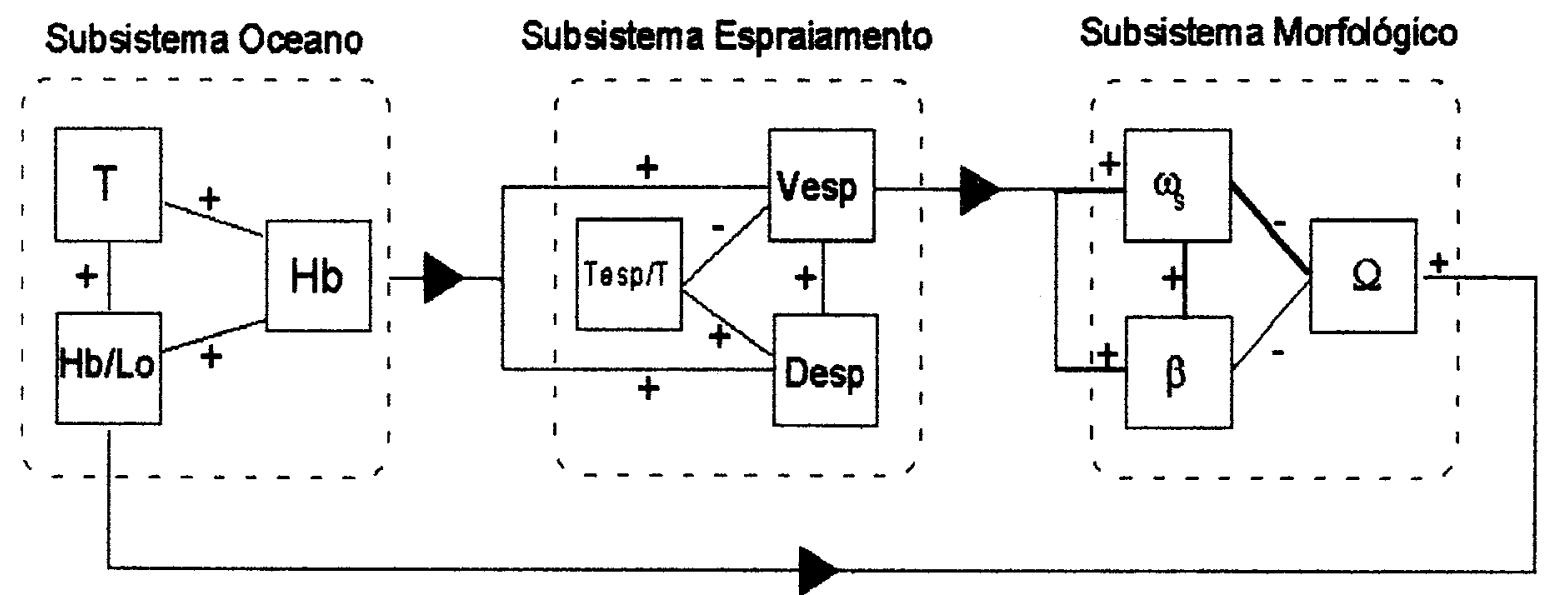

Fig. 4. Sistema processo-resposta aplicado à morfodinâmica da praia.

Considerando porém as praias isoladamente essas relações se modificam em função do estado modal de cada uma das praias (Tab. 2). É pois de se esperar que uma praia refletiva, portanto sem zona de surfe pronunciada, reflita diretamente as características das ondas, enquanto numa praia dissipativa ou intermediária a dissipação de parte da energia da onda na zona de surfe, modifica a resposta na face da praia. Assim, Lagomar é a única praia na qual a altura da onda se correlaciona, no caso positivamente, com a velocidade de decantação dos sedimentos e com a velocidade de espraiamento da onda na face da praia. A zona de surfe, portanto, funciona como um filtro modificador das características da onda, respondendo cada praia de modo próprio a esse filtro, cujas características morfológicas variam segundo as diversas tipologias dos estados praiais.

\section{Caracterização do estado praial}

A correspondência entre o estado observado e o determinado através do parâmetro de Dean $(\Omega)$ apresentou graus de acerto geralmente insatisfatórios com exceção de Lagomar cuja característica de praia refletiva levou a uma concordância de $100 \%$ entre o observado e o calculado. No outro extremo, a praia tipicamente dissipativa de Verão Vermelho, apresentou uma concordância de apenas $67 \%$ entre calculado e observado, resultado da ocorrência de areias grossas reliquiares nos sedimentos da praia, afetando a velocidade de decantação e conseqüentemente o resultado do parâmetro de Dean, que passa a apresentar um valor mais baixo do que seria correto. 
Tabela 2. Matriz de correlação linear com relações significativas ao nível de $95 \%$ de probabilidade.
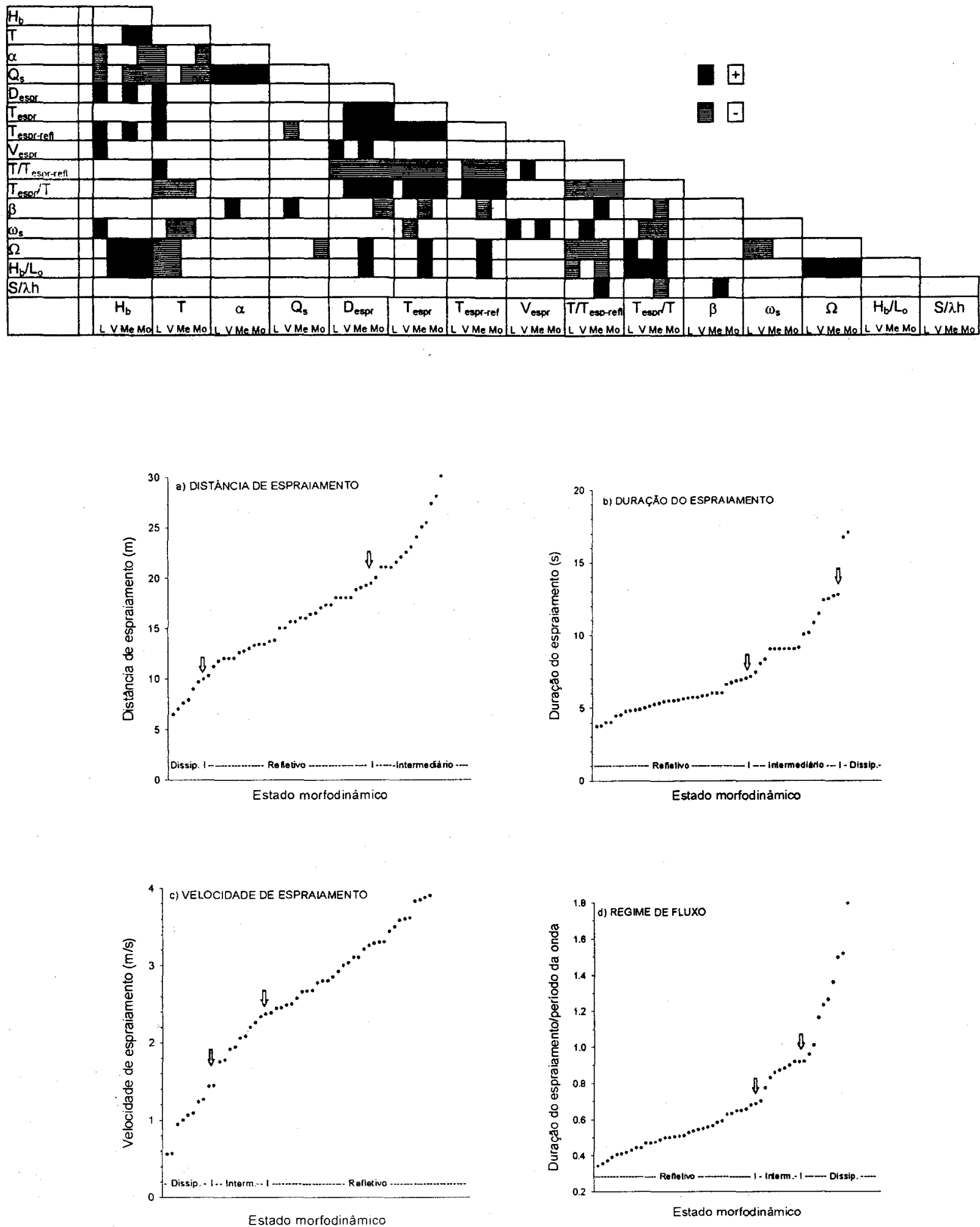

Fig. 5. Correlação gráfica entre parâmetros da zona de espraiamento da onda na face da praia e correspondente estado morfodinâmico. 
Nas duas estações da praia da Massambaba, com características de estados intermediários, as concordâncias entre observado e calculado foram de $46 \%$ para ambas as estações, sendo que Massambaba leste variou entre os estados refletivo a Terraço de Baixa Mar (TBM), Bancos Transversais (BT) e Banco e Praia de Cúspides (BPC), ao passo que em Massambaba oeste os estados mais freqüentes foram os de praia refletiva a Terraço de Baixa Mar (TBM), resultado, também, de sua granulometria mais grossa do que em Massambaba leste.

Considerando, de um lado, a concordância, insatisfatória, entre o parâmetro de Dean e o estado praial observado, e de outro, a constatação da importância da zona de espraiamento da onda na face da praia, como subsistema resultante da ação da onda modificada em maior ou menor grau pela zona de surfe, e seguindo o experimento realizado por McArdle \& McLachlan (1992) em praias do litoral sul da África do Sul e litoral do Oregon na costa oeste dos Estados Unidos, foram gerados uma série de gráficos de correlação entre parâmetros de espraiamento da onda na face da praia e do estado praial, considerando apenas aqueles estados nos quais havia concordância entre $o$ calculado e $o$ observado.

Os resultados, foram consistentes no sentido de permitir uma boa discriminação entre os diferentes estado morfodinâmicos. Assim, a distância de espraiamento aumenta rapidamente do estado dissipativo para o refletivo e o intermediário (Fig. 5a). A duração do espraiamento é menor no estado refletivo, aumenta bruscamente no estado intermediário, para se tornar muito longa no estado dissipativo, resultado da diminuição da declividade da face praial (Fig. 5b). A velocidade de espraiamento aumenta quase que linearmente do estado dissipativo para o intermediário e o refletivo (Fig. 5c), enquanto o regime de fluxo aumenta exponencialmente do estado refletivo para o intermediário e dissipativo (Fig. 5d). Este último parâmetro é especialmente interessante para a fauna bêntica pois traduz a maneira pela qual a onda reflui na face da praia, sendo que, para valores superiores a 1, o refluxo não se completa, ocorrendo um represamento, já que a freqüência de chegada de uma nova onda é muito superior ao tempo de completar o ciclo espraiamento-refluxo.

Apesar dos limites encontrados não permitirem uma discriminação entre os diversos estados intermediários e também diferirem significativamente dos encontrados por McArdle \& McLachlan (op. cit.), refletindo condições oceanográficas diferentes, a utilização de variáveis da zona de espraiamento em associação com outras, como os de clima de onda, parece promissora para o desenvolvimento de uma equação mais diagnóstica do estado praial no momento da observação do que o parâmetro de Dean. Este, por sua vez, não perde sua validade como parâmetro diagnóstico da tendência evolutiva do estado morfodinâmico em busca do equilíbrio às condições oceanográficas vigentes no momento da observação.

\section{Discussão}

A baixa diagnosticidade do parâmetro de Dean para a caracterização do estado praial, principalmente em praias de significativa variabilidade topográfica, decorre, não apenas do fato de as medidas terem sido feitas apenas num dado momento, mas principalmente pela baixa correlação entre a granulometria, ou velocidade de decantação, dos sedimentos e o gradiente da face da praia e, por extensão, do fundo marinho. A Figura 6 mostra claramente que, apesar da nítida e significativa correlação positiva $(r=0,76 ; \alpha=0,05)$ entre as variáveis consideradas quando aplicadas ao conjunto das praias analisadas, tal correlação não se mantêm quando as praias são consideradas isoladamente. Verifica-se, em particular, que a velocidade de decantação se mantêm quase invariável, enquanto o gradiente da face da praia varia muito, principalmente nas duas praias de estado intermediário.

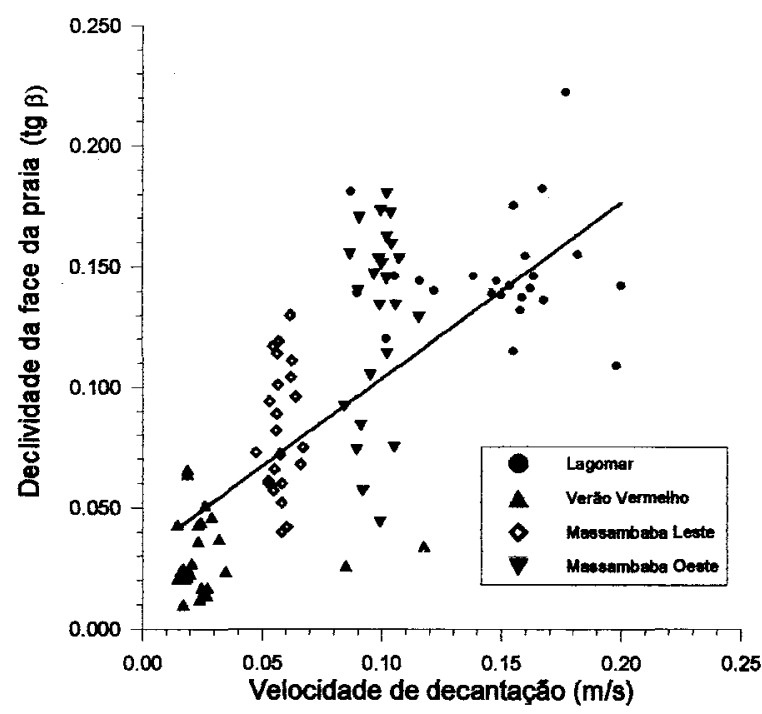

Fig. 6. Correlação gráfica entre velocidade de decantação dos sedimentos da face da praia e o gradiente da face da praia.

Uma tentativa de contornar este problema foi feita por Klein* (1997), ao substituir o parâmetro

(*) Klein, A. H. da F. 1997. Um método indireto para a determinação do estágio morfodinâmico de praias oceânicas arenosas. In: CONGRESSO DA ASSOCIAÇÃO BRASILEIRA DE ESTUDOS DO QUATERNARIO, 6. Curitiba, 1997. Resumos Expandidos. Curitiba, ABEQUA. p.76-78. 
sedimentar pela declividade $(\beta)$ da face praial, a partir da equação de Kriebel et al. (apud Masselink 1993) segundo a qual a declividade da face da praia pode ser expressa pela relação:

$$
\operatorname{tg} \beta=0,15 \Omega^{-0,5}
$$

de modo que

$$
\Omega=0,0225 / \operatorname{tg} \beta
$$

A aplicação desta fórmula às praias analisadas, apesar de aumentar o grau de concordância de 50 para $79 \%$ na praia dissipativa, em comparação com o parâmetro de Dean, piorou na caracterização das praias intermediárias, reduzindo o grau de acerto de $56 \%$ para $40 \%$, de modo que o resultado final continuou insatisfatório.

\section{Uma nova proposta de caracterização do estado morfodinâmico}

Considerando, conforme já ressaltado acima, a zona de surfe como um filtro cuja eficiência é função da sua capacidade de modificar a onda fazendo-a perder parte de sua energia, sendo esta capacidade função da morfologia do fundo (gradiente e presença de bancos e cavas), ou seja do estado morfodinâmico, a hipótese aqui formulada é de que a comparação entre os parâmetros da onda na zona de espraiamento na face da praia com os parâmetros da onda na zona de arrebentação mais externa, representa uma abordagem mais diagnóstica do estado morfodinâmico do que o parâmetro de Dean. Assim sendo, o sistema é analisado como um sistema processo-resposta onde a zona de surfe é tratada como caixa preta, sendo a entrada do sistema caracterizada pela altura e período da onda na zona de arrebentação mais externa e a saída do sistema é analisada na zona de espraiamento.

Na Figura 7 é representada a correlação gráfica entre a altura da onda na arrebentação $\left(\mathrm{H}_{b}\right)$ e a altura atingida pela onda na face da praia, sendo esta última determinada através da relação:

$$
h=\operatorname{sen} \beta \cdot D_{\text {espr }}
$$

onde $\mathrm{h}$ é a altura do espraiamento acima do refluxo máximo da onda na face da praia, $\beta$ a declividade da face da praia e $D_{\text {espr }}$ a distância de espraiamento da onda na face da praia, medida a partir da posição do refluxo máximo da onda. A relação $h / \mathrm{H}_{b}$ representa a perda de energia da onda durante seu deslocamento pela zona de surfe, sendo aqui denominada de coeficiente de dissipação. Observa-se uma boa separação entre os três estados, sendo que no estado refletivo a altura alcançada pela onda na face da praia é superior à altura da onda na arrebentação, mostrando a reduzida perda de energia cinética da mesma devido à quase ausência de uma zona de surfe. $\mathrm{O}$ contrário ocorre nas praias dissipativas, onde a altura da onda na zona de espraiamento é geralmente menos da metade da altura na arrebentação. Nos estados intermediários a altura na zona de espraiamento é também menor que na arrebentação mas a perda de energia da onda não é tão acentuada quanto no estado dissipativo.

Apesar da boa discriminação entre os estados morfodinâmicos extremos, os diferentes estados intermediários se superpõem acentuadamente ao estado dissipativo e parcialmente ao estado refletivo não permitindo a definição de limites quantitativos entre esses estados (Fig. 8).

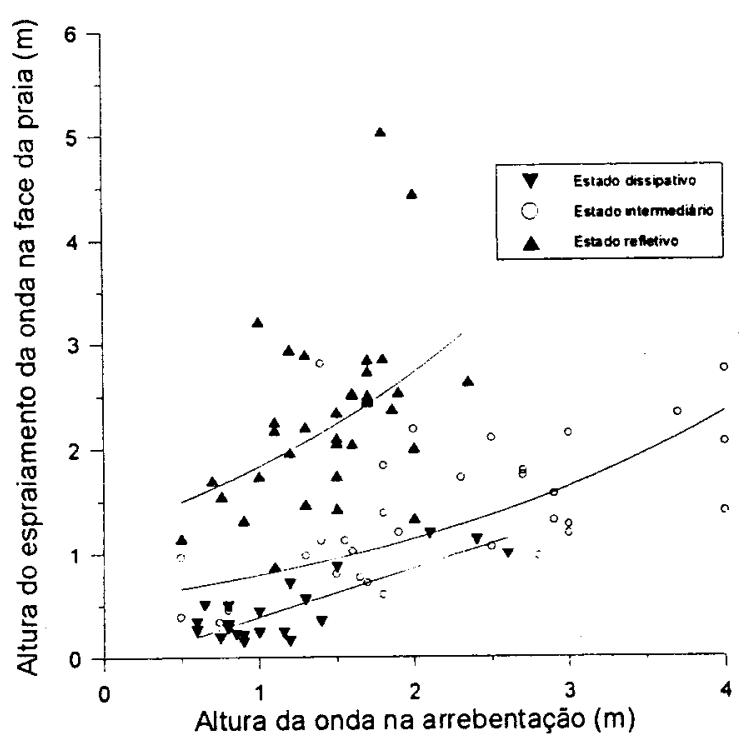

Fig. 7. Correlação gráfica entre altura da onda na arrebentação e altura do espraiamento da onda na face da praia.

Na Figura 9 é representada a correlação gráfica entre a duração do espraiamento na face da praia e o período médio das ondas, cujo quociente constitui o regime de fluxo de Kemp \& Plinstone (1968). Também neste caso ocorre uma boa discriminação entre os estados morfodinâmicos extremos, mas com superposição dos estados intermediários. Algumas tendências entretanto são interessantes de serem observadas. Assim, no estado dissipativo, a duração do espraiamento é inversamente proporcional ao 
período médio das ondas. Como nesse estado o ciclo espraiamento-refluxo geralmente não se completa antes da chegada de uma nova onda, tal dificuldade de escoamento deve se acentuar quanto menor for $o$ período, pois nessa situação há uma tendência de acavalamento de uma onda sobre a onda durante o processo de espraiamento, que assim se torna mais prolongado. No estado refletivo a duração do espraiamento apresenta pouca variação devido à grande velocidade de fluxo e forte inclinação da face da praia, enquanto que nos estados intermediários a duração do espraiamento apresenta uma tendência de aumentar com o aumento do período das ondas.

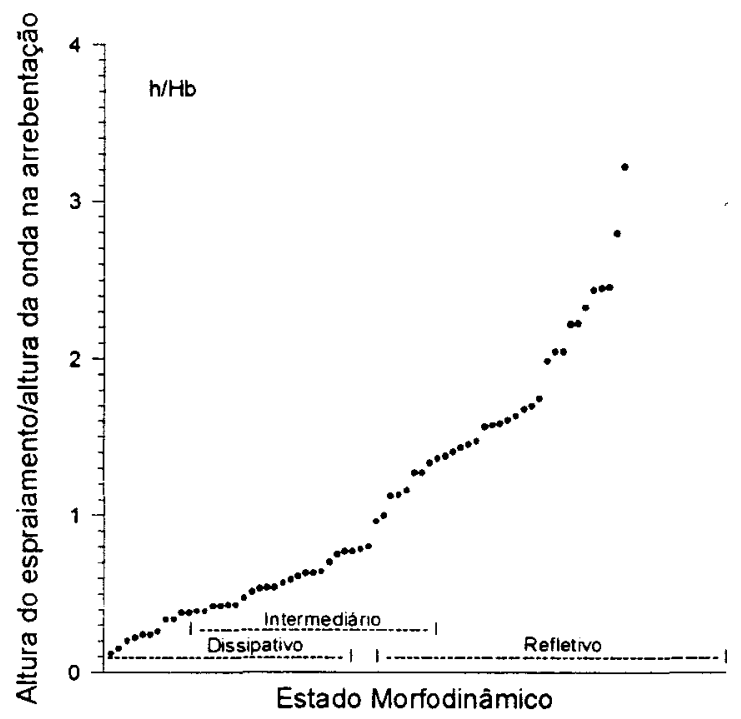

Fig. 8. Correlação gráfica entre o estado morfodinâmico e o quociente entre altura do espraiamento e a altura da onda na arrebentação.

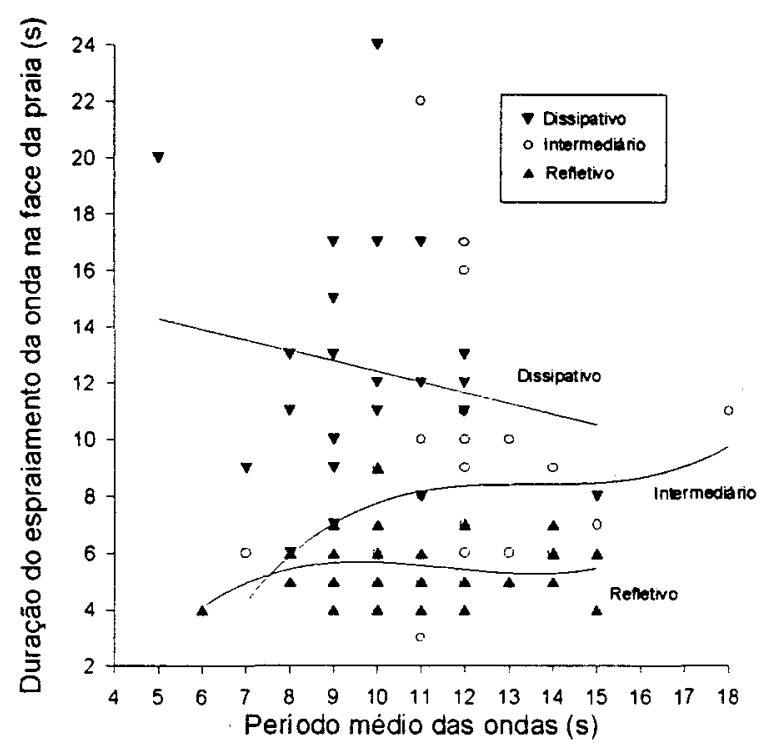

Fig. 9. Correlação gráfica entre o período médio das ondas e a duração do espraiamento na face da praia.
Associando os dois quocientes, o de dissipação e o de regime de fluxo, numa única fórmula, é obtido um novo parâmetro, aqui denominado de delta $(\Delta)$, sendo

$$
\Delta=\frac{\left(\operatorname{sen} \beta \cdot D_{e s p r}\right) / H_{b}}{T_{e s p r} / T}
$$

que assim passa a conter tanto a altura quanto o período da onda e sua modificação em direção à praia. O resultado obtido (Fig. 10), permitiu uma distinção bastante razoável entre os diferentes estados, inclusive entre os estados intermediários, com exclusão do estado "Banco e Praia de Cúspides" que não foi observado durante as campanhas realizadas, mas que não deverá se distinguir muito do estado "Banco e Calha Longitudinal".

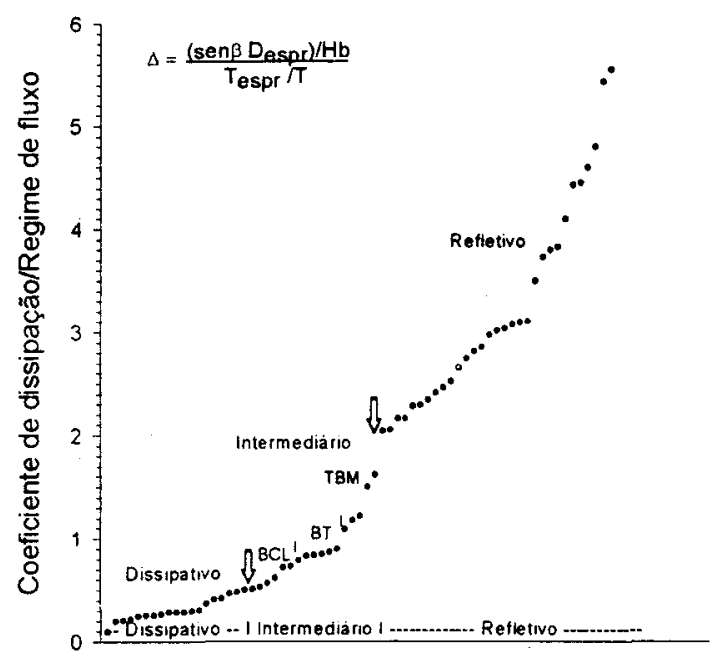

Fig. 10. Correlação gráfica entre estado morfodinâmico e o parâmetro $\Delta$ proposto.

Os limites encontrados, na área estudada, para discriminação dos diferentes estados pelo parâmetro $\Delta$ apresentaram a seguinte tendência:

Estado

Delta $(\Delta)$

Dissipativo

$<0,5$

Banco e Calha Longitudinal $\quad 0,5-0,8$

Bancos Transversais

$0,8-1,0$

Terraço de Baixa Mar

$1,0-2,0$

Refletivo

$>2,0$

Estes limites evidentemente devem ser considerados como uma primeira aproximação, sendo necessário aumentar significativamente o número de observações, tanto espacialmente, quanto em pontos 
localizados. A expectativa é de se obter um agrupamento, dentro de uma faixa modal, de valores de $\Delta$ para cada um dos estados morfodinâmicos, já que a própria dinâmica de transição de um estado para outro implica em uma certa fluidez dos limites. Não obstante à imprecisão dos limites numéricos de classificação, inerente à própria dinâmica do sistema, a abordagem aqui sugerida, ao não incorporar o erro de concepção quanto à correlação entre parâmetros sedimentológicos e gradiente topográfico, quando aplicado a uma praia isoladamente, se espera venha oferecer resultados razoavelmente consistentes na identificação do estado morfodinâmico no momento da observação.

\section{Agradecimentos}

Os recursos financeiros para a aquisição de equipamentos e diárias de campo foram fornecidos pela PETROBRAS no âmbito do projeto de Morfodinâmica de Praias (Projeto FUJB/ Geociências/PETROBRAS contrato $\mathrm{N}^{\circ}$ 650.2.127.949 Proc. FUJB 5541-7).

Participaram dos trabalhos de campo e laboratório os estudantes de mestrado em geografia Alexandre Younes Ribeiro, Aluísio Marcelo Costa Lima, Andréia Maria Lopes Bentes e Guilherme Borges Fernandez, e a graduanda em oceanografia, Maria Fernanda de Lucena Rezende. Bolsas de pósgraduação e pesquisa foram fornecidas pelo $\mathrm{CNPq}$ e CAPES.

\section{Referências bibliográficas}

Dean, R. G. 1973. Heuristic models of sand transport in the surf zone. In: CONFERENCE OF ENGINEERING DYNAMIC IN THE SURF ZONE. Sydney, 1973. Proceedings. Sidney, NSN. p.208-214.

Emery, K. O. 1938. Rapid method of mechanical analysis of sands. J. Sedim. Petrol., 8(3):105111.

Emery, K. O. 1961. A simple method of measuring beach profiles. Limnol. Oceanogr., 6:90-93.
Kemp, P. H. \& Plinston, D. T. 1968 . Beaches produced by waves of low phase difference. J. Hydraul. Div., 94(4):1183-1195.

Komar, P. D. 1976. Beach profiles and onshoreoffshore sediment transport. In: Komar, P. D. ed. Beach processes and sedimentation. Englewood Cliffs, Prentice Hall. 429p.

Komar, P. D. 1983. Beach processes and erosion - an introduction. In: Komar, P. D \& Moore, J, R. eds. CRC Handbook of coastal processes and erosion. Boca Raton, CRC Press. p.1-20.

Masselink, G. 1993. Simulating the effects of tides on beach morphodynamics. J. Coast. Res., 15:180197.

Muehe, D. 1996. Geomorfologia costeira. In: Cunha, S. B. \& Guerra, A. J. T. orgs. Geomorfologia: exercícios, técnicas e aplicações. Rio de Janeiro, Bertrand Brasil. p.191-238.

Muehe, D. \& Souza, S. R. 1997. Determinação do perfil de praia na zona de surfe e arrebentação através do emprego do trenó submarino. Notas Técnicas, 10:1-5.

Muehe, D. \& Carvalho, V. G. de, 1993. Geomorfologia, cobertura sedimentar e transporte de sedimentos na plataforma continental interna entre a Ponta de Saquarema e o Cabo Frio (RJ). Bolm Inst. oceanogr., S Paulo, 41(1/2):1-12.

McArdle, S. B. \& McLachlan, A. 1992. Sand beach ecology: swash features relevant to the macrofauna. J. Coast. Res., 8(2):398-407.

Shepard, F. P. 1950. Beach cycles in Southern California. U.S. Army Corps of Engineers. Beach Erosion Board Tech. Memo., (20):1-26.

Wright, L. D. \& Short, A. D. 1983. Morphodynamics of beaches and surf zones in Australia. In: Komar, P. D. \& Moore, J. R. eds. CRC Handbook of coastal processes and erosion. Boca Raton, CRC Press. p.35-64. 
Wright, L. D. \& Short, A. D. 1984 . Morphodynamic variability of surf zones and beaches: a synthesis. Mar. Geol., 56:93-118.

Wright, L. D.; Short, A. D. \& Green, M. O. 1985. Short-term changes in the morphodynamic states of beaches and surf zones: an empirical predictive model. Mar. Geol., 62(3-4):339-364.

(Manuscrito recebidol6 março 1998; revisado 19 junho 1998; aceito 22 outubro 1998) 